\title{
THE EFFECT OF NEGATIVE PRESSURE ON THE ANTIBACTERIAL EFFECT OF HERBAL IRRIGANT (AN IN VITRO STUDY)
}

\author{
ElSaeed Abdel Hafiz * and Adel Abdelwahed*
}

\begin{abstract}
Purpose: This study aimed to evaluate the antibacterial effect of Green tea as a root canal irrigant using Endovac irrigation System. Materials and Methods: for this study, 60 extracted human teeth were used. After their decapitation, they were instrumented using Universal ProTaper rotary files up to size F4 then separated into 2 set of groups according to the solution used in irrigation; Group A1: irrigated with $5.25 \% \mathrm{NaOCl}$ Group A2: irrigated with Green tea (30 specimens in each group). We then subdivided each group into 2 subgroups according to the technique used for irrigation; Subgroup A: using conventional irrigation and Subgroup B: using Endovac irrigation system. Samples were sterilized and inoculated with Enterococcus faecalis(ATCC29212) for $48 \mathrm{hrs}$. After irrigation, microbial samples were collected, transferred to nutrient agar and incubated for counting of bacterial colony forming units (CFUs). The significance level was $\mathrm{P} \leq 0.05$. Results: There was a statistically significant difference among the tested groups and subgroups in the mean scores of bacterial counts. Concerning the irrigating devices, there was statistically significant difference between conventional irrigation and Endovac system as Endovac showed higher antibacterial effect than conventional irrigation $(\mathrm{P} \leq 0.05)$. Green tea showed statistical significant difference with Endovac system subgroup than conventional irrigation $(\mathrm{P} \leq 0.05)$. Conclusion Endovac irrigation system was effective in eradication of $\mathrm{E}$. faecalis from the root canals using either $\mathrm{NaOCl}$ or Green tea.
\end{abstract}

KEYWORDS : Green tea, Antibacterial, Irrigation, Endovac irrigation System.

\section{INTRODUCTION}

Microorganisms and their toxic byproducts are of the commonest factors causing pulpal and periapical disease. Thorough disinfection and avoidance of microbial reinfection of root canal system are of the most substantial goals for root canal treatment.
Taking into account the complex anatomy of root canal systems and also failure of available systems in proper preparation and disinfection of root canal, as 35:80\% of canal walls remain underprepared even after its full preparation. Therefore, the combination between chemical and mechanical cleansing of root canals plays a hugely significant rule in root canal

\footnotetext{
* Lecturer of Endodontics Faculty of Oral and Dental Medicine Future University
} 
disinfection (1).

Proper and ideal irrigation of root canal is known to be considered a substantial element in the success of root canal treatment. Failure is constantly reoccurring in the majority of cases due to the presence of -almost impossible to removemicroorganisms even after proper treatment. Studies stated that almost $45.8 \%$ of failed cases are caused by $E$. faecalis, which is a gram positive facultative anaerobe capable of invading dental tubules and also capable of resisting a variety of irrigants and medicaments used in root canal treatment (2).

Sodium hypochlorite $(\mathrm{NaOCl})$ is considered to be the most frequently used irrigant in roots treatment as it is capable of melting down soft tissue, expelling debris out of canals and it also has a vastly wide effect against microorganisms as it has an inhibitory effect on the bacteria's essential proteins, in addition to its antifungal properties. It also has a number of undesired properties such as tissue toxicity, potential allergic reactions, undesirable smell and taste and its inability to remove smear layer. Therefore, several studies are being carried out to find an effective organic substitute (3).

Apple cider vinegar -made from apple cider or apple itself- it has anti-inflammatory and antibacterial characters. Those days, it is vastly used for diabetes and weight loss. Apple cider vinegar is constantly being tested by researchers in dentistry field as a chelating agent, however, few studies were directed towards its antibacterial effects, that's why our current study aims to measure the efficacy of apple cider vinegar as an antibacterial in comparison to the efficacy of $\mathrm{NaOCl}(4)$.

Conventional methods of irrigation are vastly used in clinical practice due to its simplicity of application. However, conventional methods have its limitations, as its efficacy depends upon root canal taper, apical preparation, size, design and inserted depth of the needle and irrigant flow. That's why contaminated canals' disinfection using these methods doesn't bring the best results, in addition to the presence of apical vapor lock at the root end which could negatively affect the irrigation's efficacy. Moreover, the positive pressure forming at the tip of the needle may cause extrusion of the irrigant beneath the root to the facial spaces which in turn causes accidents as $\mathrm{NaOCl}$ accidents (5).

Apical negative-pressure systems have been also used as it allows delivering the irrigant and sucking it simultaneously which allows delivering the agent along the full length of the root canal. Endovacsystem being one of the apical negative-pressure systems so, several studies spoke of its efficacy in removal of smear layers and debris from the apical one third of the canal without risking extrusion of the irrigant out of the canal thus reducing post-operative pain. On the other hand, several other studies mentioned its antibacterial effects (6). Time dependent effect of apical negative pressure (ANP), Vibringe, passive ultrasonic irrigation (PUI), non-activated SAF and conventional irrigation on the reduction of E. faecalis in experimentally infected root canals was evaluated. It came up with a conclusion that irrigation time with conventional needle is extremely affected on the reduction of the bacterial count in the root canal; but there was no significant difference between a time of 2 and 4 minutes of irrigation with the non-activated SAF, Vibringe, Endovac and PUI groups in reducing $\mathrm{E}$. faecalis counts from the root canals (7). In an in vitro study looked into the effect of time spent in performing the irrigation and the Endovac system effect as an antimicrobial. It came to a conclusion that when increasing the irrigation time, the Endovac system showed improvement in its antibacterial effect (2); Therefore, the aim of the present study was directed to evaluate the efficacy of green tea as root canal irrigant with Endovac irrigation system in eradication of $\mathrm{E}$. faecalis inside root canal. 


\section{MATERIALS AND METHODS}

\section{Sample selection and preparation}

For this study, 60 single rooted, single canaled extracted human teeth were chosen with mature apices. Radiographic images of both the mesiodistal and bucco-lingual directions were taken and used for confirming the presence of a single canal. After that, by the use of ultrasonic scaler, the teeth were cleaned out of soft tissue and deposits. The root lengths were standardized to $15 \mathrm{~mm}$ by decoronation of the tooth perpendicular to the long axis by a diamond disc.

Universal ProTaper Ni-Ti rotary files were used in a crown-down manner for root canal preparation with a 16:1 reduction hand-piece that was powered by a torque-controlled electric motor; at a rotational speed of $300 \mathrm{rpm}$ and a torque-control of $2.6 \mathrm{~N} / \mathrm{cm}$. A set of seven files were used, three shaping files (Sx, S1 and S2) for coronal 2/3 preparation and four finishing files (F1, F2, F3 and F4) for apical 1/3 to provide adequate space for the micro cannula of Endovac irrigating system. During instrumentation, $1 \mathrm{ml}$ of freshly prepared $2.6 \%$ sodium hypochlorite $(\mathrm{NaOCl})$ solution was used to irrigate the canal using a 30 gauge Navitip needle. A final rinse was done using $1 \mathrm{~mL}$ 17\% EDTA, then all the canals were dried with sterile paper points after irrigation. With the use of intermediate restorative material, the root apices were sealed and by the use of nail polish, roots surface were varnished to ensure a closed canal system. All specimens were sterilized using gamma radiation (Cobalt 60 irradiators with dose rate of $1.774 \mathrm{KGY}$ with total dose of $25 \mathrm{KGY}$ ).

\section{Biofilm development and canal inoculation:}

Sterilized brain heart infusion broth was used as a media for propagation of Enterococcus faecalis(ATCC 29212) and incubated at $37^{\circ} \mathrm{C}$ in anaerobic chamber for $24 \mathrm{hrs}$. The concentration of bacteria adjusted to $1.5 \times 10 * 8 \mathrm{CFU} / \mathrm{ml}$ which is equivalent to \#0.5 McFarland turbidity level.
All specimens were inoculated by $0.5 \mathrm{~mL}$ of the suspension using a micropipette, then the canals were sealed with intermediate restorative material and then, placed individually inside test tubes with $2 \mathrm{ml} \mathrm{BHI}$ broth, closed with cotton, inserted inside a rack and placed in the incubator at $37^{\circ} \mathrm{C}$ for $48 \mathrm{hrs}$., for allowing bacterial multiplication and proliferation. After incubation, samples were collected from each canal (S1) using sterile paper points and transferred to test tubes containing saline, after 10-fold serial dilutions in sterile saline solution, $0.2 \mathrm{~mL}$ were plated onto nutrient agar plates and incubated at $37^{\circ} \mathrm{C}$ for $48 \mathrm{hrs}$. Bacterial growth was measured by $\mathrm{CFU} / \mathrm{ml}$.

\section{Samples grouping and irrigation procedures:}

The sixty samples were divided into two main groups according to irrigation solution (A1) $\mathrm{NaOCl} \&$ (A2) Green tea with 30 specimens in each group. Each main group was subdivided into two subgroups according to irrigation technique (B1) Conventional irrigation (B2) Endovac with 15 specimens in each subgroup.

In a subgroup B1 for both main groups: For three successive cycles, a 30 gauge Navitip needle was used to deliver $1 \mathrm{ml}$ of the irrigant into the canals by an up and down motion for $30 \mathrm{sec}$., then the irrigant was left untouched for $60 \mathrm{sec}$.

In a subgroup B2 for both main groups: Samples were irrigated using Endovac irrigation system, one cycle of macro irrigation in which the syringe tip was used to deliver $1 \mathrm{ml}$ of irrigant. Simultaneously, to allow suction of the irrigant, a macro cannula was then inserted into the canal in an up and down motion for $30 \mathrm{sec}$., then, the irrigant was left untouched for $60 \mathrm{sec}$. After macro irrigation, three cycles of micro irrigation were accomplished using a micro cannula. In each cycle, micro cannula was placed at the full working length for $30 \mathrm{sec}$, to suction the irrigant during its delivering by syringe tip, then, micro cannula was removed and the irrigant was left untouched for $60 \mathrm{~s}$. 


\section{Bacterial sampling:}

After irrigation, the root canals were filled with sterile saline as a transport fluid. The sterile paper points were inserted into the canals and placed until absorbed the transport fluid and was transferred to a test tube containing $1 \mathrm{ml}$ of saline. Each sample was carefully homogenized by vortexing for 30 sec. After incubating the tubes at $37^{\circ} \mathrm{C}$ in anaerobic chamber for 4 hrs., ten-fold serial dilutions were performed and $100 \mu \mathrm{L}$ of each dilution was plated on nutrient agar and incubated at $37^{\circ} \mathrm{C}$ for $48 \mathrm{hrs}$. An automatic colony counter (Flash \& Go, IUL, S.A., Barcelona, Spain) used to measure bacterial load as it quantifies colony forming units (CFU)/ $\mathrm{ml}$.

\section{Statistical Analysis:}

Data were showed as Mean, Standard deviation (SD) values. Data were explored for normality using Kolmogorov Smirnov and Shapiro-Wilk tests and were found not to follow a normal distribution and to be positively skewed so log transformation was made. Mann Whitney U test and Wilcoxon signed rank test were used for interred and intragroup comparisons respectively. The significance level was $\mathrm{P} \leq 0.05$ for all tests. Statistical analysis was performed with IBM ${ }^{\circledR}$ SPSS ${ }^{\circledR}$ (SPSS Inc., IBM Corporation, NY, USA) Statistics for windows, version 25.5

\section{RESULTS}

\section{Descriptive statistics:}

The highest mean and standard deviation value of bacterial count was found in (A2B1) (Green tea, Conventional irrigation) $(3.90 \pm 0.50)$ with the least antibacterial effect followed by (A1B1) ( NaOCl, Conventional irrigation) $(2.50 \pm 0.77)$ then (A2B2) (Green tea, Endovac system) (1.66 \pm 0.97$)$ while the lowest $($ mean \pm SD) value was scored by (A1B2) $(\mathrm{NaOCl}$, Endovac system) $(0.67 \pm 0.78)$ with the highest antibacterial effect (Fig. 1).

\section{Effect of Irrigating solution:}

After irrigation, there was a statistically significant difference between $(\mathrm{NaOCl})$ and (green tea) groups where $(\mathrm{p} \leq 0.05)$. The highest mean and standard deviation value was found in (Green tea (A2)) $(2.78 \pm 1.37)$ with less antibacterial effect, while the least mean and standard deviation value was found in $(\mathrm{NaOCl}(\mathrm{A} 1))(1.58 \pm 1.20)$ with higher antibacterial effect.

\section{Effect of Irrigation technique:}

After irrigation, there was a statistically significant difference between (Conventional irrigation (B1)) and (Endovac (B2)) subgroups where ( $\mathrm{p} \leq 0.05)$. The highest mean and standard deviation value was found in (Conventional irrigation (B1)) (3.20 \pm 0.95$)$

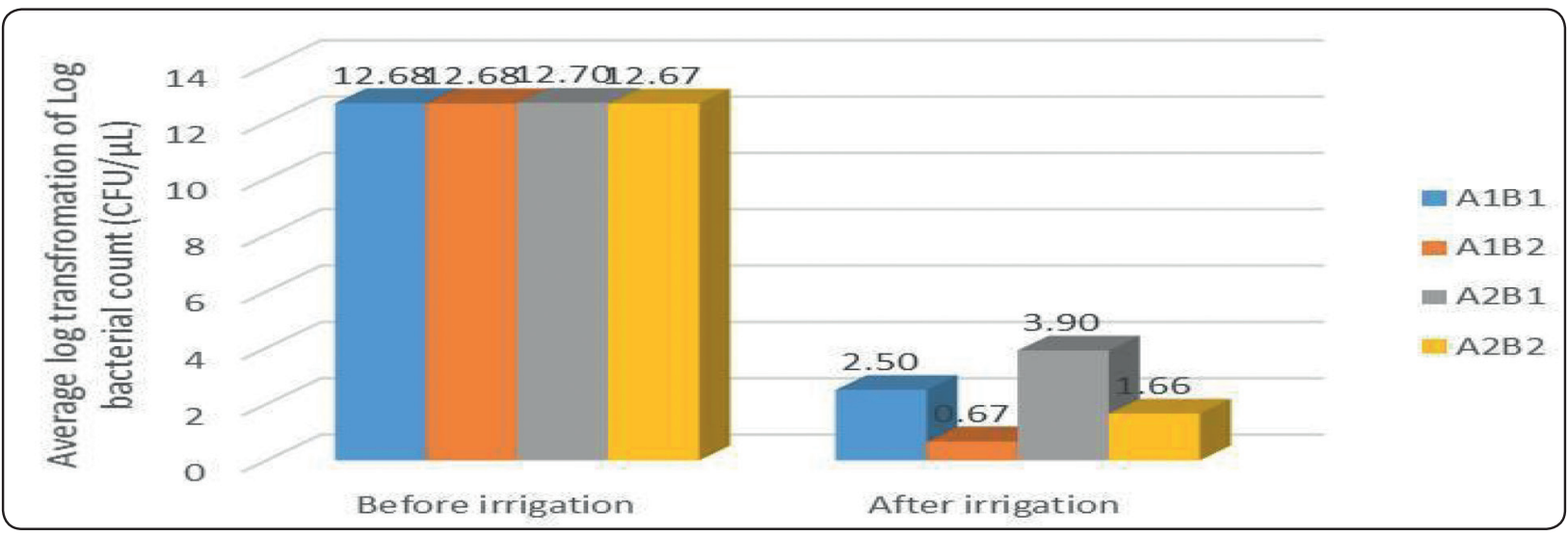

Fig. (1): Bar chart showing average Log bacterial count $(\mathrm{CFU} / \mu \mathrm{L})$ for different groups and subgroups before and after irrigation 
with less antibacterial effect, while the least mean and standard deviation value was found in (Endovac (B2)) (1.16 \pm 1.00$)$ with higher antibacterial effect.

\section{Effect of Irrigation technique within each Ir- rigating solution:}

Within $(\mathrm{NaOCl}$ (A1)) and (Green tea (A2)) Groups, after irrigation, there was a statistically significant difference between (Conventional irrigation (B1)) and (Endovac (B2)) subgroups where $(\mathrm{p} \leq 0.05)$.

$\mathrm{NaOCl}$ (A1) group: The highest mean and standard deviation value of bacterial count was found in (Conventional irrigation (B1)) subgroup $(2.50 \pm 0.77)$ with less antibacterial effect, while the least mean and standard deviation values of bacterial count was found in (Endovac (B2)) subgroup $(0.67 \pm 0.78)$ with higher antibacterial effect.

Green tea (A2) group: The highest mean and standard deviation values of bacterial count was found in (Conventional irrigation (B1)) subgroup $(3.90 \pm 0.50)$ with less antibacterial effect, while the least mean 865and standard deviation value of bacterial count was found in (Endovac (B2)) subgroup (1.66 \pm 0.97$)$ with higher antibacterial effect.

\section{Effect of Irrigating solution within each Irri- gation technique:}

Within (Conventional irrigation (B1)) and (Endovac (B2)) subgroups, after irrigation, there was a statistically significant difference between $(\mathrm{NaOCl}(\mathrm{A} 1))$ and (Green tea (A2)) groups where $(\mathrm{p} \leq 0.05)$.

Conventional irrigation (B1) subgroup: The highest mean and standard deviation value of bacterial count was found in (Green tea (A2)) group (3.90 \pm 0.50$)$ with less antibacterial effect, while the least mean and standard deviation value was found in $(\mathrm{NaOCl}(\mathrm{A} 1))(1.66 \pm 0.78)$ with higher antibacterial effect.

Endovac (B2) subgroup: the highest mean and standard deviation value of bacterial count was found in (Green tea (A2)) group (1.66 \pm 0.78$)$ with less antibacterial effect while the least mean and standard deviation value of bacterial count was found in $(\mathrm{NaOCl}$ (A1)) group $(0.67 \pm 0.78)$ with higher antibacterial effect (Fig. 2).

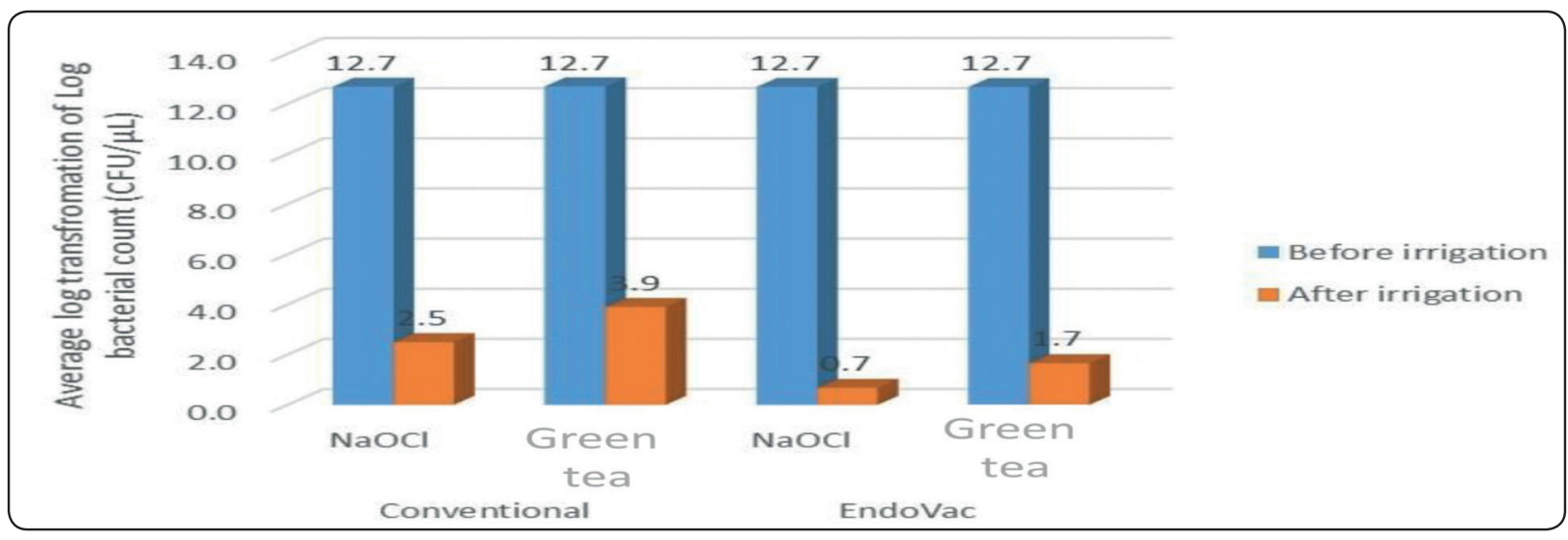

Fig. (2): Bar chart showing average Log bacterial count $(\mathrm{CFU} / \mu \mathrm{L})$ before and after irrigation for different types of Irrigating solutions within each Irrigation technique 


\section{DISCUSSION}

The existence of microorganisms within root canals is in the form of free-floating cellular entities and dense plaque-like biofilms. The free-floating form is easier to get rid of from the root canal and is more likely to be eradicated by antimicrobial agents; On the 7 other hand, the resistance of bacteria in mature biofilms may exceed 1000 -fold more. To ensure the success of root canal treatment, it is substantial to destroy the bacterial biofilms (8); Therefore, the present study was directed to evaluate the efficacy of green tea as root canal irrigant using Endovac irrigation system in eradication of $\mathrm{E}$. faecalis inside the root canal.

The result of the tested irrigation $\mathrm{A} 1(\mathrm{NaOCl})$, and A2 (Green tea) in present study regardless the irrigating techniques used in the study showed that there was a statistically significant difference between both groups. The highest mean value of bacterial count was found in (Green tea) group with less antibacterial effect while the least mean value of bacterial count was found in $(\mathrm{NaOCl})$ group with higher antibacterial effect. In explanation of the highest antibacterial effect of $\mathrm{NaOCl}$, it was found to be due to the high $\mathrm{pH}$ of $\mathrm{NaOCl}$ which irreversibly inhibits enzymatic activity, alters cellular metabolism biosynthesis and degrades phospholipids which in turn interferes with the cytoplasmic integrity (9).

Our findings agree with observation of a study which stated that plain apple cider vinegar significantly reduced the $\mathrm{E}$. faecalis numbers after mechanical instrumentation but still less remarkable than that of sodium hypochlorite when used alone or in combination with green tea (10), But these finding are in contradiction with the results reached by another study in which there were a similarity in antimicrobial effect of both 5\% sodium hypochlorite and apple cider vinegar (4). This difference in the findings might be due to the difference methods. The latter study was done on micro-titer plates not on natural teeth as in our study. In addition, it is in need for further testing to find quantitative analysis rather than its qualitative analysis of the antimicrobial activity of apple cider vinegar.

The use of Endovac irrigation system in the current study showed more antibacterial action compared to the conventional irrigation regardless of irrigation solution, that there was a statistically significant difference between (conventional irrigation) and (Endovac) where the highest mean value of bacterial count was found in (conventional irrigation) with less antibacterial effect while the least mean value of bacterial count was found in (Endovac group) with higher antibacterial effect.

Obtained results in our study were found to agree with other researches which proved Endovac system to be the most effective in debridement and disinfection of the root canal system in comparison to conventional irrigation (11), in another study, the efficacy of Endovac irrigation system to be remarkably better in comparison to the manual irrigation system in primary molars with less extrusion of irrigant amount and better irrigant penetration depth into the dentinal tubule (12). In another study, after only $48 \mathrm{hrs}$. of incubation, the efficiency of Endovac irrigation system in removing a thick biofilm of E. faecalis in mesial roots of mandibular molars is established, while after 48 hrs, some of those roots irrigated using conventional irrigation were still found positive (13). Another study agreed with our study, compared the antimicrobial effectiveness of Endovac system, and conventional irrigation. Out of 16 mandibular molars which was treated with conventional method, negative culture was found in $67 \%$ while $100 \%$ among the Endovac irrigation group (14).

But, our results are in contradiction with an another study that claimed that there is no difference between the two groups; However, "The original Endovac protocol" recommends the use of 5.25 $\% \mathrm{NaOCl}$ (15), Almost all studies investigating the efficacy of Endovac have used concentrations of $\mathrm{NaOCl}$ ranging between 2.5 and $6 \%$. Using 0.5 
$\% \mathrm{NaOCl}$ in this study could be the reason for the absence of significant differences in antimicrobial action between Endovac irrigation and conventional irrigation.

\section{CONCLUSION}

Based upon the end results of this study it could be concluded that:

1. Out of all the irrigation protocols, none of them totally eradicated E. faecalis, But $\mathrm{NaOCl}$ was found to be more effective in eradicating $\mathrm{E}$. faecalis than Green tea.

2. Endovac irrigation system showed promising action in reducing E. faecalis in root canal system.

3. When combining green tea with the use of Endovac, it gives more promising results than combining $\mathrm{NaOCl}$ with the use of conventional technique.

\section{REFERENCES}

1. Siqueira JF, Alves FR, Versiani MA, et al. Correlative bacteriologic and micro-computed tomographic analysis of mandibular molar mesial canals prepared by Self-Adjusting File, Reciproc, and Twisted File systems. J Endod 2013; 39:1044-50.

2. Zenga C, Meghilb MM, Millerb M, Gou Y. Antimicrobial efficacy of an apical negative pressure root canal irrigation system against intracanal microorganisms. J Dent. 2018; 72:71-5.

3. Gonçalves LS, Rodrigues RC, Andrade Junior CV, Soares RG, Vettore MV. The effect of sodium hypochlorite and chlorhexidine as irrigant solutions for root canal disinfection: A systematic review of clinical trials. J Endod 2016; 42:527-32. 3 .

4. Mohanty S, Ramesh S, Muralidharan NP. Antimicrobial efficacy of apple cider vinegar against Enterococcus faecalis and Candida albicans: An in vitro study. Advanced Pharmacy Education \& Research J. 2017; 7:137-41.

5. Abdelglil SA, Farag AM, El-Hediny HA, Darrag AM. Efficacy of Endovac system and needle irrigation on root canal debridement. Tant Dent J. 2016; 13:171-178.
6. Cohenca N, Heilborn C, Johnson JD, Flores DS, Ito IY, Silva LA. Apical negative pressure irrigation versus conventional irrigation plus triantibioticintracanal dressing on root canal disinfection in dog teeth, Oral Surg. Oral Med. Oral Pathol. Oral Radiol. Endod.2010; 109:42-6.

7. Karataş E, Uyanık MH, Abbas A, Özsu D, Arslan H. The time dependent effect of various irrigation systems on the reduction of $\mathrm{E}$. faecalis in experimentally infected root canals. Turk Endod J 2016; 1:23-9.

8. Aksel H and Serper A. Concentration and time-dependent effect of initial sodium hypochlorite on the ability of QMix and ethylenediaminetetraacetic acid to remove smear layer. J Conserv Dent. 2017; 20: 185-9.

9. Farzaneh S, Parirokh M, Nakhaee N, Abbott PV. Effect of two different concentrations of sodium hypochlorite on postoperative pain following gsingle-visit root canal treatment: a tripleblindrandomized clinical trial. IntEndod $\mathrm{J}$. 2018; 51:9-11.

10. Dornelles-Morgental R, Guerreiro-Tanomaru JM, de FariaJúnior NB, Hungaro-Duarte MA. Antibacterial efficacy of endodontic irrigating solutions and their combinations in root canals contaminated with Enterococcus faecalis. Oral Surg Oral Med Oral Pathol Oral RadiolEndod 2011; 112:396-400.

11. Konstantinidi E, Psimma Z, Chavez de Paz LE, Boutsioukis C. Apical negative pressure irrigation versus syringe irrigation: a systematic review of cleaning and disinfection of the root canal system. IntEndod J. 2017; 50:1034-54.

12. Venumbaka N, Baskaran P, Mungara J, Chenchugopal M, Elangovan A, Vijayakumar P Comparative Evaluation of the Efficacy of Endovac and Conventional Irrigating Systems in Primary Molars - An in Vitro Study. JOCPD. 2018; 42:140-5.

13. Hockett JL, Dommisch JK, Johnson JD, Cohenca N. Antimicrobial efficacy of two irrigation techniques in tapered and non-tapered canal preparations: An in vitro study.2008; 34:1374-7.

14. Cohenca N, Paranjpe A, Heilborn C, Jd J. Antimicrobial efficacy of two irrigation techniques in tapered and nontapered canal preparations. A randomized controlled clinical trial. Quintessence Int. 2013; 44:2017-28.

15. Pawar R, Alqaied A, Safavi K, Boyko J, Kaufman B. Influence of an apical negative pressure irrigation system on bacterial elimination during endodontic therapy: a prospective randomized clinical study. J Endod. 2012; 38:1177-81. 